\title{
Application and Performance of 3D Printing in Nanobiomaterials
}

\author{
Wenyong Liu, Ying Li, Jinyu Liu, Xufeng Niu, Yu Wang, and Deyu Li \\ Key Laboratory for Biomechanics and Mechanobiology of Ministry of Education, School of Biological Science and Medical Engineering, \\ Beihang University, Beijing 100191, China
}

Correspondence should be addressed to Wenyong Liu; wyliu@buaa.edu.cn and Deyu Li; deyuli@buaa.edu.cn

Received 14 June 2013; Accepted 7 August 2013

Academic Editor: Xiaoming Li

Copyright (C) 2013 Wenyong Liu et al. This is an open access article distributed under the Creative Commons Attribution License, which permits unrestricted use, distribution, and reproduction in any medium, provided the original work is properly cited.

3D printing (3DP) is becoming a research and development focus in nanobiomaterials as it can quickly and accurately fabricate any desired 3D tissuemodel only if its size is appropriate. The different material powders (with different dimensional scales) and the printing strategies are the most direct factors influencing 3DP quality. With the development of nanotechnologies, 3DP is adopted more frequently for its rapidness in fabrication and precision in geometry. The fabrication in micro/nanoscale may change the performance of biomaterials and devices because it can retain more anisotropy of biomaterials compared with the traditionally rapid prototyping techniques. Thus, the biosafety issue is especially concerned by many researchers and is investigated in performance and safety of biomaterials and devices. This paper investigates the performance of 3DP in fabrication of nanobiomaterials and devices so as to partially explain how 3DP influences the performance and safety of nanobiomaterials.

\section{Introduction}

$3 \mathrm{D}$ printing $(3 \mathrm{DP})$ is becoming a research and development focus in many fields including not only traditional industries but also biomedicine and biology as it can quickly and accurately fabricate any desired 3D model only if its size is appropriate [1-3]. As one of the rapid prototyping (RP) technologies, the term of 3DP is proposed by Professor Sachs from the Massachusetts Institute of Technology (MIT) [4]. It is conceptually defined as a method for directly digital manufacturing that provides capabilities for creating a wide range of object geometries (including internal channels) in a broad variety of materials, including just about anything that is available as a spreadable powder such as ceramic, metal, metal-ceramic composite, and polymeric materials [5]. That is to say, the different material powders (with different dimensional scales) and the printing strategies are the most direct factors influencing 3DP quality $[6,7]$.

Nanotechnology provides new opportunities towards the development of better, smart medical systems and devices that have the possibility to profoundly impact therapeutic techniques with better device- (biomaterial-) cell interaction performance [8-11]. It is known that most biological cells are on the order of $100-1000 \mu \mathrm{m}$, and components of cells are on the order of nanometers [12-14]. Cell-cell interactions and cell-biomaterial interactions are microscale events [15]. Device interactions refer to the micro- and nanoscales, creating devices that will interact with cells on the microlevel which potentially alleviate extreme damage to entire tissues or even organs and reduce inflammatory response while better targeting and treating the problem [16-18]. This kind of device- (biomaterial-) cell interaction performance has promoted wide application of various nanomaterials in biomedicine and biology [19-22], such as gold [23, 24] or $\mathrm{SiO}_{2}$-gold nanoshells [25], water-soluble polymers [26], hydrogels [27], starch-based powders [28], and fibrins $[16,29]$. These biomaterials have been used for fabricating different medical devices including neuron-adhesive patterns $[30,31]$, collagen scaffolds [32, 33], synthetic biodegradable scaffolds [34-36], and fibrin channels [27]. Among the 3D nanoscale fabrication techniques, 3DP is adopted more frequently for its rapidness in fabrication and precision in geometric shape and dimensions [37].

The fabrication in micro/nanoscales may change the performance of biomaterials and devices because it can retain more anisotropy of materials compared with the traditional 
RP techniques [38, 39]. Thus, the biosafety issue is especially concerned by many researchers [40,41]. The newly emerging concepts such as biofabrication [42], bioprinting [43], and nanoimprint lithography $[44,45]$ are also preliminarily investigated in performance and safety of biomaterials and devices.

This paper intends to investigate the performance of 3DP in fabrication of nanobiomaterials and devices so as to partially explain how 3DP influences the performance and safety of nanobiomaterials. Firstly, the 3DP concept is introduced, and the workflow is summarized. Then, the related techniques and their applications in nanobiomaterials are analyzed.

\section{3DP for Nanobiomaterials}

2.1. Workflow and Performance of 3DP. The 3DP workflow can be described in 3 sequential steps: (1) the powder supply system platform is lifted and the fabrication platform is lowered one layer; (2) the roller spreads the polymer powder into a thin layer; (3) a print-head prints a liquid binder that bonds the adjacent powder particles together [46]. Cycling steps (1) to (3) can fabricate a 3D object.

3DP can realize quick fabrication because this technique needs no dedicated clamp or mold tools to stabilize operation targets [47]. Only four operations may limit the process rate: the application of the powder layers, the printing of the binder, the infiltration of the binder into the powder, and the drying of the binder. A recent detailed review on 3DP concerning all processing steps, such as powder-binder selection and interaction, was given by Utela et al. [5].

3DP can achieve accurate geometry [48]. The structure of geometry is always characterized by the minimum attainable feature size and the variability of geometric dimensions [46]. Both depend strongly on the binder droplet-powder particle interactions. Factors that determine the final object dimensions are the local and accumulative accuracy of deposited layer thickness, the accuracy of droplet placement, the reproducibility of the spread of the printed droplets, and the reproducibility of dimensional changes that accompany binder cure [49]. At the same time, the interaction performance of powder and binder also influences the geometric accuracy which is influenced by powder material, powder surface treatment, powder size and size distribution, powder shape, powder packing density, binder material, binder viscosity, binder surface tension, droplet size, droplet velocity, temperature of the powder and binder, and ambient temperature [49].

2.2. 3DP Techniques for Nanobiomaterials. Two kinds of 3DP techniques are mostly adopted for nanobiomaterials fabrication. One is the inkjet printing with the typical printers such as the NP 2.1 (GeSim, Germany) [50] and the Z402 (Zcorp, USA) [28]. The other is the nanoimprint lithography with the typical printers such as the EVG620 nanoimprinter [51] and the 520 hot embosser (EV Group, Austria) [52].

2.2.1. Bonding-Based Inkjet Printing. The bonding-based inkjet printing technology was developed by MIT. This procedure deposits a stream of microparticles of a binder biomaterial over the surface of a powder bed, joining particles together where the object is to be formed. A piston lowers the powder bed so that a new layer of powder can be spread over the surface of the previous layer and then selectively joined to it. After the building process, the unbounded powder is removed, and the porous model must be strengthened by a conventional presintering process [53].

According to different working modes, the inkjet printing technique is divided into the drop-on-demand (DOD) catalog in which electrical signals are used to control the ejection of an individual droplet and the continuous ejection catalog in which the ink emerges continuously from a nozzle under pressure [54]. The DOD catalog is composed of the electromechanical (piezoactuated and electrostatic actuated), the electrothermal (thermal actuated), and the electrostatic vacuum. The continuous ejection catalog is composed of the electrofield-controlled inkjet and the Hertz continuous inkjet (mutual charged droplet repulsion type) (see [46] for more technical details).

The bonding-based inkjet printing has been adopted for fabricating many tissue modes with micro/nanobiomaterials. Woo et al. [55] employed the 3DP with particulate-leaching to create porous scaffolds using polylactide-coglycolide (PLGA) powder mixed with salt particles and a suitable organic solvent. Hepatocytes were successfully attached to the scaffolds. Baca et al. [56] found that the cell viability organization of bio/nanointerface can be accomplished during the inkjet printing or selective wetting processes allowing patterning of cellular arrays and even spatially defined genetic modification. Cui and Boland [57] used a modified thermal inkjet printer and demonstrated the feasibility of printing microvasculature with human microvascular endothelial cell suspension in thrombin solutions onto fibrinogen solutions, which served as the substrate. The printed cells achieved the capacity to interact and proliferate within fibrin channels forming a tubular lining.

2.2.2. Bioink-Jet Printing. The bioink-jet printing technology was developed along the concept of cell printing proposed by Yan et al. [58]. This process prints gels, single cells, and cell aggregates offering a possible solution for organ printing [5961]. To be used for cell printing, the thermal or piezotip printheads and ink cartridges are modified to allow bioinks to be printed [62]. These bioinks usually consist of aqueous media, thermoreversible polymers, or polymer/hydrogel precursors combined with living cells [63].

Laser-assisted cell-printing techniques have also been developed [63]. These techniques comprise the so-called laser guidance direct write (LGDW). The LGDW process was the first reported technique to print viable cells by forming patterns of embryonic chick spinal-cord cells on a glass slide. Shortly after this, modified laser-induced forward transfer (LIFT) techniques and modified inkjet printing were also used to print viable cells and proteins, followed by the recently introduced electrohydrodynamic jetting (EHDJ) method [63].

2.2.3. Nanoimprint Lithography. The nanoimprint lithography (NIL) is a fast and cost-efficient technique for fabricating 
nanostructures. The procedure of NIL is to stack multiple layers of such structures on top of each other; that is, a finished double-layer of structures is covered with a spacerlayer which is planarized using the chemical-mechanical polishing so that a second layer can be processed on top. This process is a new and unique possibility to stack structure patterns by transferring structures several times on the same substrate and can therefore be used to build up 3D nanobiomaterials in a fast and cost-efficient way. Bergmair et al. [64] have fabricated a 3D stacking of gold structures like fishnet structures using NIL and demonstrated its industrial application value.

\section{Performance of 3DP for Nanobiomaterials}

Recent advances in the understanding of nanobiomaterials and nanotechnology have released a promising perspective for intelligent biomaterials and devices such as the bone [2, 65], the valve [66], the vessel [67], and the artificial ear [68]. $3 \mathrm{DP}$ as a newly emerging technology is a kind of an effective tool to obtain such tissues or devices. In contrast to traditional fabrication techniques generally subtracting material step by step (a top-down approach), 3DP approaches allow nearly unlimited designs and a large variety of materials to be used for biomedical engineering and biology.

3.1. Performance of 3DP. $3 \mathrm{DP}$ is derived from traditional RP technologies; therefore, it inherits advantages of RP solution in other industries [5]. For a powder-based process, the preand postprocessing of $3 \mathrm{DP}$ is similar to RP, but $3 \mathrm{DP}$ can be used to create shapes that are more difficult or impossible to be created. Fierz et al. [69] specially registered and quantitatively compared the shape of the 3D-printed hydroxyapatite scaffolds with that of their tomograms. It confirmed the accuracy and suitability of the 3D-printed scaffolds for potential clinical applications [70]. On the other hand, the thermal postprocessing steps for ceramics and metals are similar to those in traditional powder-based methods and do not require the potentially extensive laser optimization of selective laser sintering (SLS) [71] and selective laser melting (SLM) [72].

The drawback of traditional 3DP is that the objects require postprocessing and typically have considerable porosity (even after initial thermal treatment), while SLS and SLM objects come out of the machine fully dense (SLM) or already sintered (SLS) and ready for infiltration. The polymer field does not have the same 3DP parallels as metals and ceramics (because processing in a powder state is less common), but tissue engineering in particular has steps that are adaptable to 3DP because scaffold fabrication often begins with microspheres of the correct sizes for 3DP [73]. In addition to the fabrication flexibility of 3DP, these adaptive abilities of 3DP make it a powerful tool as a modifier to a traditional fabrication procedure, as opposed to the complete procedure reinvention required when using new materials in other RP systems.

3DP application in nanobiomaterials can preserve, optimize, and even modify characteristics of materials [74, 75].
Wu et al. [76] fabricated hierarchical and tough mesoporous bioactive glass (MBG) scaffolds to prepare hierarchical and multifunctional MBG scaffolds with excellent mechanical strength and mineralization ability for application in bone regeneration by a modified 3DP technique using polyvinyl alcohol (PVA) as a binder. They showed that the MBG scaffolds fabricated by 3DP possess a high mechanical strength about 200 times higher than that of traditional polyurethane foam-templated MBG scaffolds due to a highly controllable pore architecture and PVA binder. Excellent apatite mineralization ability and sustained drug delivery properties could be obtained by a hierarchical pore structure composed of large pores (several hundred micrometers to $1.3 \mathrm{~mm}$ ) as well as well-ordered mesopores $(5 \mathrm{~nm})$. As aforementioned, although many methods can be used to solve the hierarchical porous scaffold design and fabrication problem, those methods cannot provide the precise and easy control over complicated hierarchical pore architectures within the scaffolds. Therefore, a more general method for designing the hierarchical internal structures with complex combinations of pore morphologies is required [77]. Bergmann et al. [2] manufactured customized implants for maxillofa$\mathrm{cial} /$ craniofacial bone replacement using the 3DP technique. The four-point bending strength of the printed specimens was $14.9 \mathrm{MPa}$ after sintering which made it possible to print tailored bone substitute implants using a bioactive tricalcium phosphate (TCP)/glass composite. Besides, powder-based systems can also be used to produce rougher surfaces, which may enhance cell adhesion [78].

\subsection{Biosafety of 3DP Nanobiomaterials and Devices. As 3DP} can produce very accurate organs regarding the aspect of geometric structure even in biological characteristics, the safety issues cannot be ignored [40]. Main issues include the biosafety, the identity safety, and the personal privacy safety [79]. Among these issues, the biosafety is mostly related to the human health [80]. Thus, the availability of biocompatible powder-binder systems is a key safety issue for 3DP $[81,82]$.

From the aspect of biocompatibility, Sachs et al. defined the basic requirements for binder systems [49]: (1) a high binder content while still having a low viscosity so that it is capable of being deposited by the print-head; (2) minimal conductivity for continuous-jet printing heads; (3) the rapid dry speed of binder so that the next layer of particles can be spread. For example, in scaffold fabrication, the powder can be a pure powder or surface-coated powder, depending on the application of the scaffold $[28,83,84]$. It is possible to use a single, one-component powder or a mixture of different powders blended together.

Another aspect of biosafety is biodegradation. Taking the synthetic implant as an example, the partial biodegradation of implant is not on a priori advantage for the patient in every case, because remaining fragments can weaken the mechanical strength of the new grown bone $[83,85]$. Thus, the biodegradation behavior of the implants should be improved by optimizing the phase composition and porosity. The formation of new tissue should also be stimulated by the addition of growth factors or other pharmaceuticals [2]. 


\section{Conclusions}

This paper summarized the application and performance of the 3DP in nanobiomaterials along with an investigation of currently available literature to support each 3DP technique and application performance. A clear understanding of the $3 \mathrm{DP}$ concept and process can help the user take advantage of the considerable biomaterial flexibility of 3DP and speed the development of new nanobiomaterial and binder systems. The goal here is to provide a unified presentation of the state of the art so as to understand new biomaterial combinations and characteristics via the $3 \mathrm{DP}$ process.

It seems to be effective to combine multiple fabrication methods to obtain a single object. For instance, combining electrospinning (nanoporosity) and bioplotting (microporosity) for the production of a single scaffold was demonstrated by Kim et al. [86]. The combined effect of different techniques will most likely exhibit positive cooperative effects. Thus, instead of focusing on the exploitation of single technique, it would be most fruitful to combine the positive effects of different techniques into one operation procedure.

A wide range of biocompatible nanomaterials is available, ranging from metals and metallic alloys to ceramics and polymers. Several techniques have shown potentials for processing composite materials that combine synthetic materials and biological ones, such as cells, proteins, and growth factors.

The rapidly growing 3DP has shown opportunities for nanobiomaterials applications although it still faces significant challenges. Relevant challenges to be addressed in the future include the following: (1) fundamentally understanding the printing processes and convergence of techniques for the best and the most affordable healthcare; (2) developing in situ manufacturing strategies, such as in situ tissue engineering; (3) investigating toxicity evolution as toxicity is an important factor for nanobiomaterials; (4) standardizing processes, design, and metrology tools; (5) regulating the application so as to effectively protect the personal privacy $[87,88]$. Besides, the multidisciplinarily cooperation among material scientists, engineers, and clinicians should be enhanced so as to facilitate further developments and the clinical translation [89].

\section{Acknowledgments}

This work was supported by the National Natural Science Foundation of China (Grants nos. 11272039 and 11272038), the 111 Project (no. B13003), and the Fundamental Research Funds for the Central Universities of China.

\section{References}

[1] T. A. Campbell and O. S. Ivanova, "3D printing of multifunctional nanocomposites," Nano Today, vol. 8, no. 2, pp. 119-120, 2013.

[2] C. Bergmann, M. Lindner, W. Zhang et al., "3D printing of bone substitute implants using calcium phosphate and bioactive glasses," Journal of the European Ceramic Society, vol. 30, no. 12, pp. 2563-2567, 2010.
[3] P. Danilevičius, S. Rekštytė, E. Balčiūnas et al., "Laser 3D micro/nanofabrication of polymers for tissue engineering applications," Optics \& Laser Technology, vol. 45, pp. 518-524, 2013.

[4] M. Cima, E. Sachs, T. L. Fan, J. F. Bredt, S. P. Michaels, and S. Khanuja, "Three dimensional printing techniques," US Patent 5204055, 1993.

[5] B. Utela, D. Storti, R. Anderson, and M. Ganter, "A review of process development steps for new material systems in three dimensional printing (3DP)," Journal of Manufacturing Processes, vol. 10, no. 2, pp. 96-104, 2008.

[6] F. P. W. Melchels, J. Feijen, and D. W. Grijpma, "A review on stereolithography and its applications in biomedical engineering," Biomaterials, vol. 31, no. 24, pp. 6121-6130, 2010.

[7] D. Yoo, "New paradigms in internal architecture design and freeform fabrication of tissue engineering porous scaffolds," Medical Engineering \& Physics, vol. 34, no. 6, pp. 762-776, 2012.

[8] F. Guillemot, A. Souquet, S. Catros et al., "High-throughput laser printing of cells and biomaterials for tissue engineering," Acta Biomaterialia, vol. 6, no. 7, pp. 2494-2500, 2010.

[9] X. M. Li, H. F. Liu, X. F. Niu et al., "The use of carbon nanotubes to induce osteogenic differentiation of human adipose-derived MSCs in vitro and ectopic bone formation in vivo," Biomaterials, vol. 33, no. 19, pp. 4818-4827, 2012.

[10] X. M. Li, Q. L. Feng, X. H. Liu, W. Dong, and F. H. Cui, "Collagen-based implants reinforced by chitin fibres in a goat shank bone defect model," Biomaterials, vol. 27, no. 9, pp. 1917-1923, 2006.

[11] S. Koutsopoulos, "Molecular fabrications of smart nanobiomaterials and applications in personalized medicine," Advanced Drug Delivery Reviews, vol. 64, no. 13, pp. 1459-1476, 2012.

[12] K.-I. Chen, B.-R. Li, and Y.-T. Chen, "Silicon nanowire fieldeffect transistor-based biosensors for biomedical diagnosis and cellular recording investigation," Nano Today, vol. 6, no. 2, pp. 131-154, 2011.

[13] F. Lautenschlager and M. Piel, "Microfabricated devices for cell biology: all for one and one for all," Current Opinion in Cell Biology, vol. 25, no. 1, pp. 116-124, 2013.

[14] X. M. Li, H. F. Liu, X. f. Niu et al., "Osteogenic differentiation of human adipose-derived stem cells induced by osteoinductive calcium phosphate ceramics," Journal of Biomedical Materials Research B, vol. 97, no. 1, pp. 10-19, 2011.

[15] H. Shin, "Fabrication methods of an engineered microenvironment for analysis of cell-biomaterial interactions," Biomaterials, vol. 28, no. 2, pp. 126-133, 2007.

[16] M. Caldorera-Moore and N. A. Peppas, "Micro- and nano tech-nologies for intelligent and responsive biomaterial-based medical systems," Advanced Drug Delivery Reviews, vol. 61, no. 15, pp. 1391-1401, 2009.

[17] X. M. Li, C. A. van Blitterswijk, Q. L. Feng, F. Z. Cui, and F. M. Watari, "The effect of calcium phosphate microstructure on bone-related cells in vitro," Biomaterials, vol. 29, no. 23, pp. 3306-3316, 2008.

[18] X. Liu, X. Li, Y. Fan et al., "Repairing goat tibia segmental bone defect using scaffold cultured with mesenchymal stem cells," Journal of Biomedical Materials Research B, vol. 94, no. 1, pp. 44-52, 2010.

[19] X. Li, Y. Fan, and F. Watari, "Current investigations into carbon nanotubes for biomedical application," Biomedical Materials, vol. 5, no. 2, Article ID 022001, 2010.

[20] H. N. Kim, A. Jiao, N. S. Hwang et al., "Nanotopography-guided tissue engineering and regenerative medicine," Advanced Drug Delivery Reviews, vol. 65, no. 4, pp. 536-558, 2013. 
[21] K. Liu, Y. Tian, and L. Jiang, "Bio-inspired superoleophobic and smart materials: design, fabrication, and application," Progress in Materials Science, vol. 58, no. 4, pp. 503-564, 2013.

[22] X. M. Li, H. Gao, M. Uo et al., "Maturation of osteoblast-like SaoS2 induced by carbon nanotubes," Biomedical Materials, vol. 4, no. 1, Article ID 015005, 2009.

[23] D. E. Owens III, J. K. Eby, Y. Jian, and N. A. Peppas, “Temperature-responsive polymer-gold nanocomposites as intelligent therapeutic systems," Journal of Biomedical Materials Research A, vol. 83, no. 3, pp. 692-695, 2007.

[24] M. Tanaka, Y. Mabuchi, T. Hayashi, and M. Hara, "Subtractive offset printing for fabrication of sub micrometer scale electrodes with gold nanoparticles," Microelectronic Engineering, vol. 95, pp. 14-20, 2012.

[25] M. Bikram, A. M. Gobin, R. E. Whitmire, and J. L. West, "Temperature-sensitive hydrogels with $\mathrm{SiO} 2-\mathrm{Au}$ nanoshells for controlled drug delivery," Journal of Controlled Release, vol. 123, no. 3, pp. 219-227, 2007.

[26] R. Landers and R. Mulhaupt, "Desktop manufacturing of complex objects, prototypes and biomedical scaffolds by means of computer-assisted design combined with computer-guided 3D plotting of polymers and reactive oligomers," Macromolecular Materials and Engineering, vol. 282, no. 9, pp. 17-21, 2000.

[27] H. Nomura, Y. Katayama, M. S. Shoichet, and C. H. Tator, "Complete spinal cord transection treated by implantation of a reinforced synthetic hydrogel channel results in syringomyelia and caudal migration of the rostral stump," Neurosurgery, vol. 59, no. 1, pp. 183-192, 2006.

[28] C. X. F. Lam, X. M. Mo, S. H. Teoh, and D. W. Hutmacher, "Scaffold development using 3D printing with a starch-based polymer," Materials Science and Engineering C, vol. 20, no. 1-2, pp. 49-56, 2002.

[29] T. Xu, C. A. Gregory, P. Molnar et al., "Viability and electrophysiology of neural cell structures generated by the inkjet printing method," Biomaterials, vol. 27, no. 19, pp. 3580-3588, 2006.

[30] N. E. Sanjana and S. B. Fuller, "A fast flexible ink-jet printing method for patterning dissociated neurons in culture," Journal of Neuroscience Methods, vol. 136, no. 2, pp. 151-163, 2004.

[31] X. M. Li, Y. Huang, L. S. Zheng et al., "Effect of substrate stiffness on the functions of rat bone marrow and adipose tissue derived mesenchymal stem cells in vitro," Journal of Biomedical Materials Research A, 2013.

[32] W.-Y. Yeong, C.-K. Chua, K.-F. Leong, M. Chandrasekaran, and M.-W. Lee, "Comparison of drying methods in the fabrication of collagen scaffold via indirect rapid prototyping," Journal of Biomedical Materials Research B, vol. 82, no. 1, pp. 260-266, 2007.

[33] G. A. Fielding, A. Bandyopadhyay, and S. Bose, "Effects of silica and zinc oxide doping on mechanical and biological properties of 3D printed tricalcium phosphate tissue engineering scaffolds," Dental Materials, vol. 28, no. 2, pp. 113-122, 2012.

[34] T. Boland, X. Tao, B. J. Damon et al., "Drop-on-demand printing of cells and materials for designer tissue constructs," Materials Science and Engineering C, vol. 27, no. 3, pp. 372-376, 2007.

[35] A. Butscher, M. Bohner, S. Hofmann, L. Gauckler, and R. Müller, "Structural and material approaches to bone tissue engineering in powder-based three-dimensional printing," Acta Biomaterialia, vol. 7, no. 3, pp. 907-920, 2011.

[36] X. Li, X. Liu, W. Dong et al., "In vitro evaluation of porous poly(L-lactic acid) scaffold reinforced by chitin fibers," Journal of Biomedical Materials Research B, vol. 90, no. 2, pp. 503-509, 2009.
[37] N. C. Rivron, J. Rouwkema, R. Truckenmüller, M. Karperien, J. de Boer, and C. A. van Blitterswijk, "Tissue assembly and organization: developmental mechanisms in microfabricated tissues," Biomaterials, vol. 30, no. 28, pp. 4851-4858, 2009.

[38] X. M. Li, L. Wang, Y. B. Fan, Q. L. Feng, F. Z. Cui, and F. Watari, "Nanostructured scaffolds for bone tissue engineering," Journal of Biomedical Materials Research A, vol. 101, no. 8, pp. 24242435, 2013.

[39] C. Liu, Z. Xia, and J. T. Czernuszka, "Design and development of three-dimensional scaffolds for tissue engineering," Chemical Engineering Research and Design, vol. 85, no. 7, pp. 1051-1064, 2007.

[40] J.-X. Cheng, "Research on the bio-safety of nanomaterials," in Proceedings of the International Conference on Computer Science and Network Technology (ICCSNT '11), pp. 2716-2719, December 2011.

[41] M. W. Jang, B. K. Jin, S. H. Lee et al., "Effect of PMMA and Cross-linked Dextran mixture on bio-safety and volume in rat," Tissue Engineering and Regenerative Medicine, vol. 7, no. 1, pp. 57-63, 2010.

[42] P. Bajaj, V. Chan, J. H. Jeong, P. Zorlutuna, H. Kong, and R. Bashir, "3-D biofabrication using stereolithography for biology and medicine," in Proceedings of the Annual International Conference of the Ieee Engineering in Medicine and Biology Society (EMBC '12), pp. 6805-6808, 2012.

[43] S. Tasoglu and U. Demirci, "Bioprinting for stem cell research," Trends in Biotechnology, vol. 31, no. 1, pp. 10-19, 2013.

[44] S. Sant, S. L. Tao, O. Z. Fisher, Q. Xu, N. A. Peppas, and A. Khademhosseini, "Microfabrication technologies for oral drug delivery," Advanced Drug Delivery Reviews, vol. 64, no. 6, pp. 496-507, 2012.

[45] C. L. Randall, T. G. Leong, N. Bassik, and D. H. Gracias, "3D lithographically fabricated nanoliter containers for drug delivery," Advanced Drug Delivery Reviews, vol. 59, no. 15, pp. 15471561, 2007.

[46] T. Billiet, M. Vandenhaute, J. Schelfhout, S. van Vlierberghe, and P. Dubruel, "A review of trends and limitations in hydrogelrapid prototyping for tissue engineering," Biomaterials, vol. 33, no. 26, pp. 6020-6041, 2012.

[47] L. Ciocca, F. de Crescenzio, M. Fantini, and R. Scotti, "CAD/CAM and rapid prototyped scaffold construction for bone regenerative medicine and surgical transfer of virtual planning: a pilot study," Computerized Medical Imaging and Graphics, vol. 33, no. 1, pp. 58-62, 2009.

[48] A. Kain, C. Mueller, and H. Reinecke, "High aspect ratio- and 3D- printing of freestanding sophisticated structures," Procedia Chemistry, vol. 1, no. 1, pp. 750-753, 2009.

[49] E. Sachs, M. Cima, and J. Cornie, "Three-dimensional printing: rapid tooling and prototypes directly from a CAD model," CIRP Annals-Manufacturing Technology, vol. 39, no. 1, pp. 201-204, 1990.

[50] P. Marizza, S. S. Keller, and A. Boisen, "Inkjet printing as a technique for filling of micro-wells with biocompatible polymers," Microelectronic Engineering, vol. 111, pp. 391-395, 2013.

[51] S. Waid, H. D. Wanzenboeck, M. Muehlberger, and E. Bertagnolli, "Optimization of 3D patterning by Ga implantation and reactive ion etching (RIE) for nanoimprint lithography (NIL) stamp fabrication," Microelectronic Engineering, vol. 97, pp. 105108, 2012.

[52] S. S. Keller, N. Feidenhans'L, N. Fisker-Bødker et al., "Fabrication of biopolymer cantilevers using nanoimprint lithography," Microelectronic Engineering, vol. 88, no. 8, pp. 2294-2296, 2011. 
[53] P. Bartolo, J. P. Kruth, J. Silva et al., "Biomedical production of implants by additive electro-chemical and physical processes," CIRP Annals-Manufacturing Technology, vol. 61, no. 2, pp. 635-655, 2012.

[54] J. R. Castrejón-Pita, G. D. Martin, S. D. Hoath, and I. M. Hutchings, "A simple large-scale droplet generator for studies of inkjet printing," Review of Scientific Instruments, vol. 79, no. 7, Article ID 075108, 2008.

[55] J. H. Woo, D. Y. Kim, S. Y. Jo, H. Kang, and I. Noh, "Modification of the bulk properties of the porous poly(lactide-co- glycolide) scaffold by irradiation with a cyclotron ion beam with high energy for its application in tissue engineering," Biomedical Materials, vol. 4, no. 4, Article ID 044101, 2009.

[56] H. K. Baca, E. C. Carnes, C. E. Ashley et al., "Cell-directed-assembly: directing the formation of nano/bio interfaces and architectures with living cells," Biochimica et Biophysica Acta, vol. 1810, no. 3, pp. 259-267, 2011.

[57] X. Cui and T. Boland, "Human microvasculature fabrication using thermal inkjet printing technology," Biomaterials, vol. 30, no. 31, pp. 6221-6227, 2009.

[58] K. C. Yan, K. Paluch, K. Nair, and W. Sun, "Effects of process parameters on cell damage in a $3 \mathrm{~d}$ cell printing process," in Proceedings of the ASME International Mechanical Engineering Congress and Exposition (IMECE '09), pp. 75-81, November 2009.

[59] G. Mendonça, D. B. S. Mendonça, L. G. P. Simões et al., “The effects of implant surface nanoscale features on osteoblastspecific gene expression," Biomaterials, vol. 30, no. 25, pp. 40534062, 2009.

[60] V. Mironov, R. P. Visconti, V. Kasyanov, G. Forgacs, C. J. Drake, and R. R. Markwald, "Organ printing: tissue spheroids as building blocks," Biomaterials, vol. 30, no. 12, pp. 2164-2174, 2009.

[61] T. Xu, J. Jin, C. Gregory, J. J. Hickman, and T. Boland, "Inkjet printing of viable mammalian cells," Biomaterials, vol. 26, no. 1, pp. 93-99, 2005.

[62] J. Jagur-Grodzinski, "Polymers for tissue engineering, medical devices, and regenerative medicine. Concise general review of recent studies," Polymers for Advanced Technologies, vol. 17, no. 6, pp. 395-418, 2006.

[63] B. R. Ringeisen, C. M. Othon, J. A. Barron, D. Young, and B. J. Spargo, "Jet-based methods to print living cells," Biotechnology journal, vol. 1, no. 9, pp. 930-948, 2006.

[64] I. Bergmair, M. Mühlberger, K. Hingerl et al., "3D materials made of gold using Nanoimprint Lithography," Microelectronic Engineering, vol. 87, no. 5-8, pp. 1008-1010, 2010.

[65] G. A. Fielding, A. Bandyopadhyay, and S. Bose, "Effects of silica and zinc oxide doping on mechanical and biological properties of 3D printed tricalcium phosphate tissue engineering scaffolds," Dental Materials, vol. 28, no. 2, pp. 113-122, 2012.

[66] L. de Bartolo, A. Leindlein, D. Hofmann et al., "Bio-hybrid organs and tissues for patient therapy: a future vision for 2030," Chemical Engineering and Processing, vol. 51, pp. 79-87, 2012.

[67] V. Mironov, V. Kasyanov, and R. R. Markwald, "Nanotechnology in vascular tissue engineering: from nanoscaffolding towards rapid vessel biofabrication," Trends in Biotechnology, vol. 26, no. 6, pp. 338-344, 2008.

[68] T. M. Cervantes, E. K. Bassett, A. Tseng et al., "Design of composite scaffolds and three-dimensional shape analysis for tissueengineered ear," Journal of the Royal Society Interface, vol. 10, no. 87, pp. 1-9, 2013.
[69] F. C. Fierz, F. Beckmann, M. Huser et al., “The morphology of anisotropic 3D-printed hydroxyapatite scaffolds," Biomaterials, vol. 29, no. 28, pp. 3799-3806, 2008.

[70] J. M. Sobral, S. G. Caridade, R. A. Sousa, J. F. Mano, and R. L. Reis, "Three-dimensional plotted scaffolds with controlled pore size gradients: effect of scaffold geometry on mechanical performance and cell seeding efficiency," Acta Biomaterialia, vol. 7, no. 3, pp. 1009-1018, 2011.

[71] W. Y. Zhou, S. H. Lee, M. Wang, W. L. Cheung, and W. Y. Ip, "Selective laser sintering of porous tissue engineering scaffolds from poly(L-lactide)/carbonated hydroxyapatite nanocomposite microspheres," Journal of Materials Science, vol. 19, no. 7, pp. 2535-2540, 2008.

[72] J. P. Kruth, L. Froyen, J. van Vaerenbergh, P. Mercelis, M. Rombouts, and B. Lauwers, "Selective laser melting of iron-based powder," Journal of Materials Processing Technology, vol. 149, no. 1-3, pp. 616-622, 2004.

[73] A. J. Marshall and B. D. Ratner, "Quantitative characterization of sphere-templated porous biomaterials," AIChE Journal, vol. 51, no. 4, pp. 1221-1232, 2005.

[74] P. Colombo, E. Bernardo, and G. Parcianello, "Multifunctional advanced ceramics from preceramic polymers and nano-sized active fillers," Journal of the European Ceramic Society, vol. 33, no. 3, pp. 453-469, 2013.

[75] S. H. Eom, S. Senthilarasu, P. Uthirakumar et al., "Preparation and characterization of nano-scale $\mathrm{ZnO}$ as a buffer layer for inkjet printing of silver cathode in polymer solar cells," Solar Energy Materials and Solar Cells, vol. 92, no. 5, pp. 564-570, 2008.

[76] C. Wu, Y. Luo, G. Cuniberti, Y. Xiao, and M. Gelinsky, “Threedimensional printing of hierarchical and tough mesoporous bioactive glass scaffolds with a controllable pore architecture, excellent mechanical strength and mineralization ability," Acta Biomaterialia, vol. 7, no. 6, pp. 2644-2650, 2011.

[77] D. Yoo, "New paradigms in hierarchical porous scaffold design for tissue engineering," Materials Science \& Engineering C, vol. 33, no. 3, pp. 1759-1772, 2013.

[78] A. Tirella, F. Vozzi, C. de Maria et al., "Substrate stiffness influences high resolution printing of living cells with an ink-jet system," Journal of Bioscience and Bioengineering, vol. 112, no. 1, pp. 79-85, 2011.

[79] R. Faddoul, N. Reverdy-Bruas, A. Blayo, and B. Khelifi, "Inkjet printing of silver nano-suspensions on ceramic substratessintering temperature effect on electrical properties," Microelectronic Engineering, vol. 105, pp. 31-39, 2013.

[80] X. M. Li, L. Wang, Y. B. Fan, Q. L. Feng, and F. Z. Cui, "Biocompatibility and toxicity of nanoparticles and nanotubes," Journal of Nanomaterials, vol. 2012, Article ID 548389, 19 pages, 2012.

[81] X. M. Li, H. Gao, M. Uo et al., "Effect of carbon nanotubes on cellular functions in vitro," Journal of Biomedical Materials Research A, vol. 91, no. 1, pp. 132-139, 2009.

[82] X. M. Li, Y. Yang, Y. B. Fan, Q. L. Feng, F. Z. Cui, and F. Watari, "Biocomposites reinforced by fibers or tubes, as scaffolds for tissue engineering or regenerative medicine," Journal of Biomedical Materials Research A, 2013.

[83] H. Seyednejad, D. Gawlitta, R. V. Kuiper et al., "In vivo biocompatibility and biodegradation of $3 \mathrm{D}$-printed porous scaffolds based on a hydroxyl-functionalized poly( $\varepsilon$-caprolactone)," Biomaterials, vol. 33, no. 17, pp. 4309-4318, 2012.

[84] M. Flaibani and N. Elvassore, "Gas anti-solvent precipitation assisted salt leaching for generation of micro- and nano-porous 
wall in bio-polymeric 3D scaffolds," Materials Science and Engineering C, vol. 32, no. 6, pp. 1632-1639, 2012.

[85] X. M. Li, X. Liu, J. Huang, Y. B. Fan, and F.-Z. Cui, "Biomedical investigation of CNT based coatings," Surface and Coatings Technology, vol. 206, no. 4, pp. 759-766, 2011.

[86] G. Kim, J. Son, S. Park, and W. Kim, "Hybrid process for fabricating $3 \mathrm{D}$ hierarchical scaffolds combining rapid prototyping and electrospinning," Macromolecular Rapid Communications, vol. 29, no. 19, pp. 1577-1581, 2008.

[87] J.-X. Wang, Y.-B. Fan, Y. Gao, Q.-H. Hu, and T.-C. Wang, “TiO2 nanoparticles translocation and potential toxicological effect in rats after intraarticular injection," Biomaterials, vol. 30 , no. 27 , pp. 4590-4600, 2009.

[88] J. X. Wang, Y. Gao, Y. Hou et al., "Evaluation on cartilage morphology after intra-articular injection of titanium dioxide nanoparticles in rats," Journal of Nanomaterials, vol. 2012, Article ID 452767, 11 pages, 2012.

[89] Q. Lian, D.-C. Li, Y.-P. Tang, and Y.-R. Zhang, "Computer modeling approach for a novel internal architecture of artificial bone," Computer Aided Design, vol. 38, no. 5, pp. 507-514, 2006. 

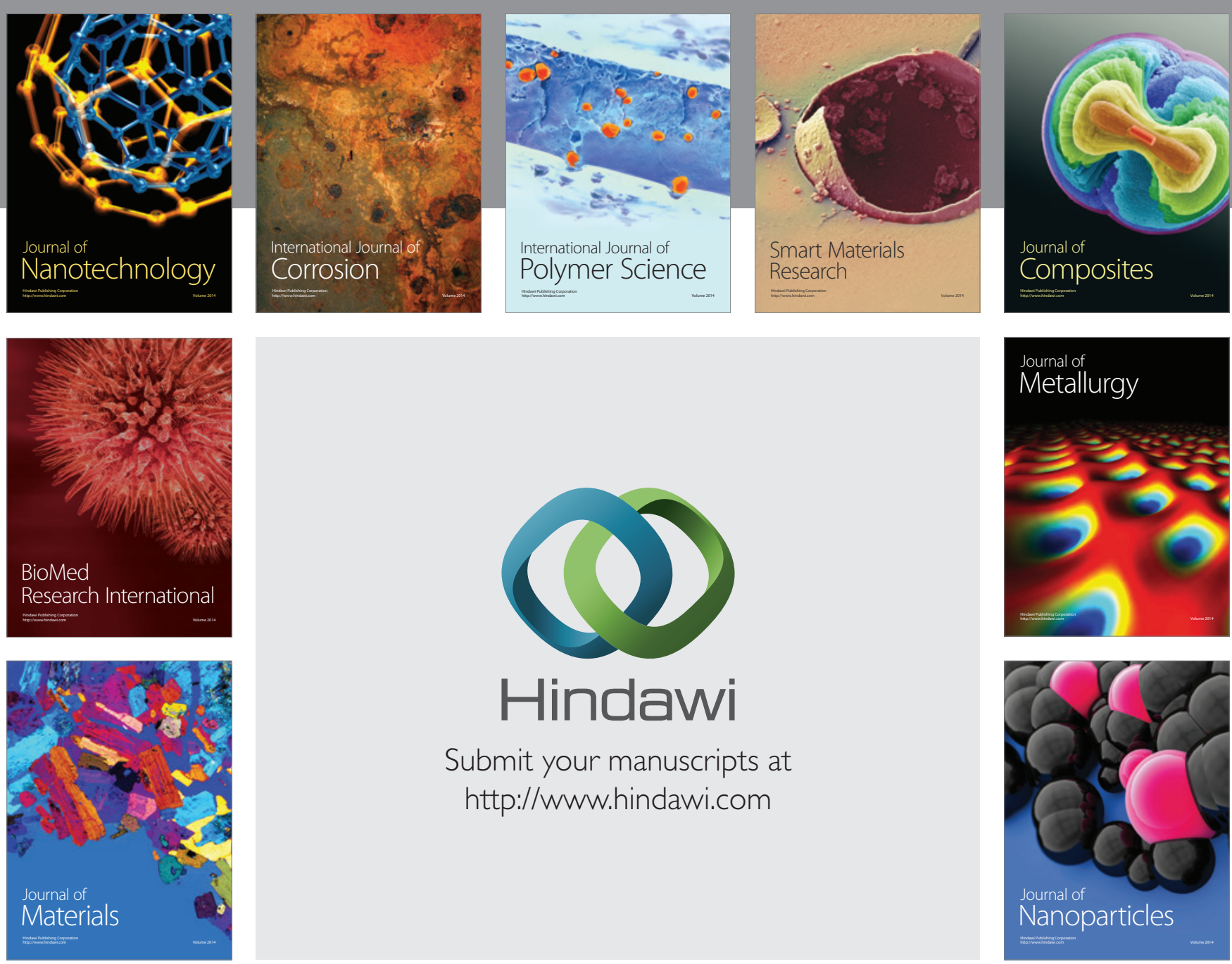

Submit your manuscripts at http://www.hindawi.com
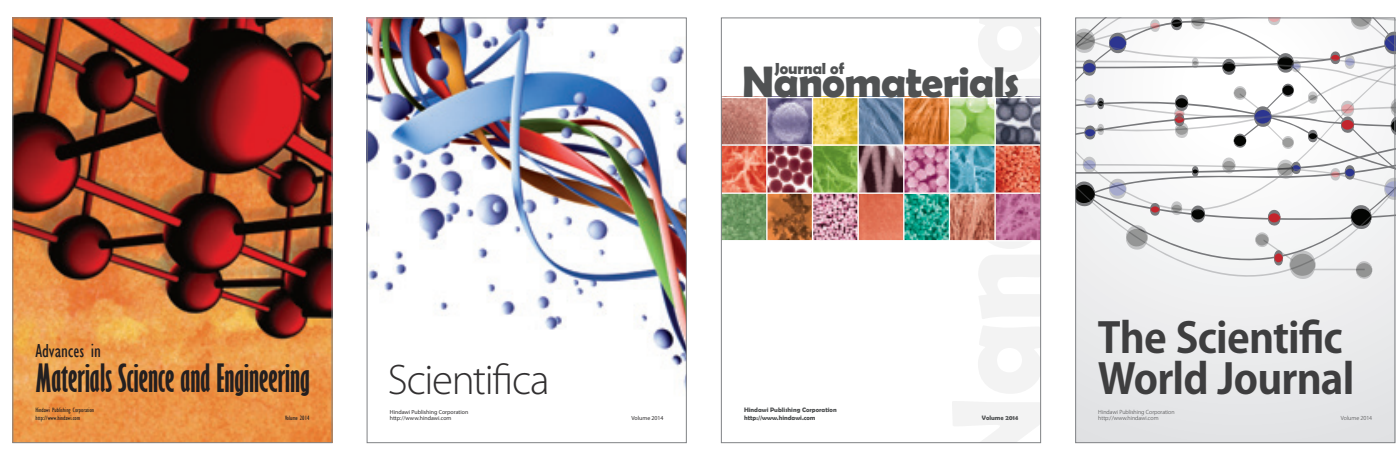

\section{The Scientific World Journal}
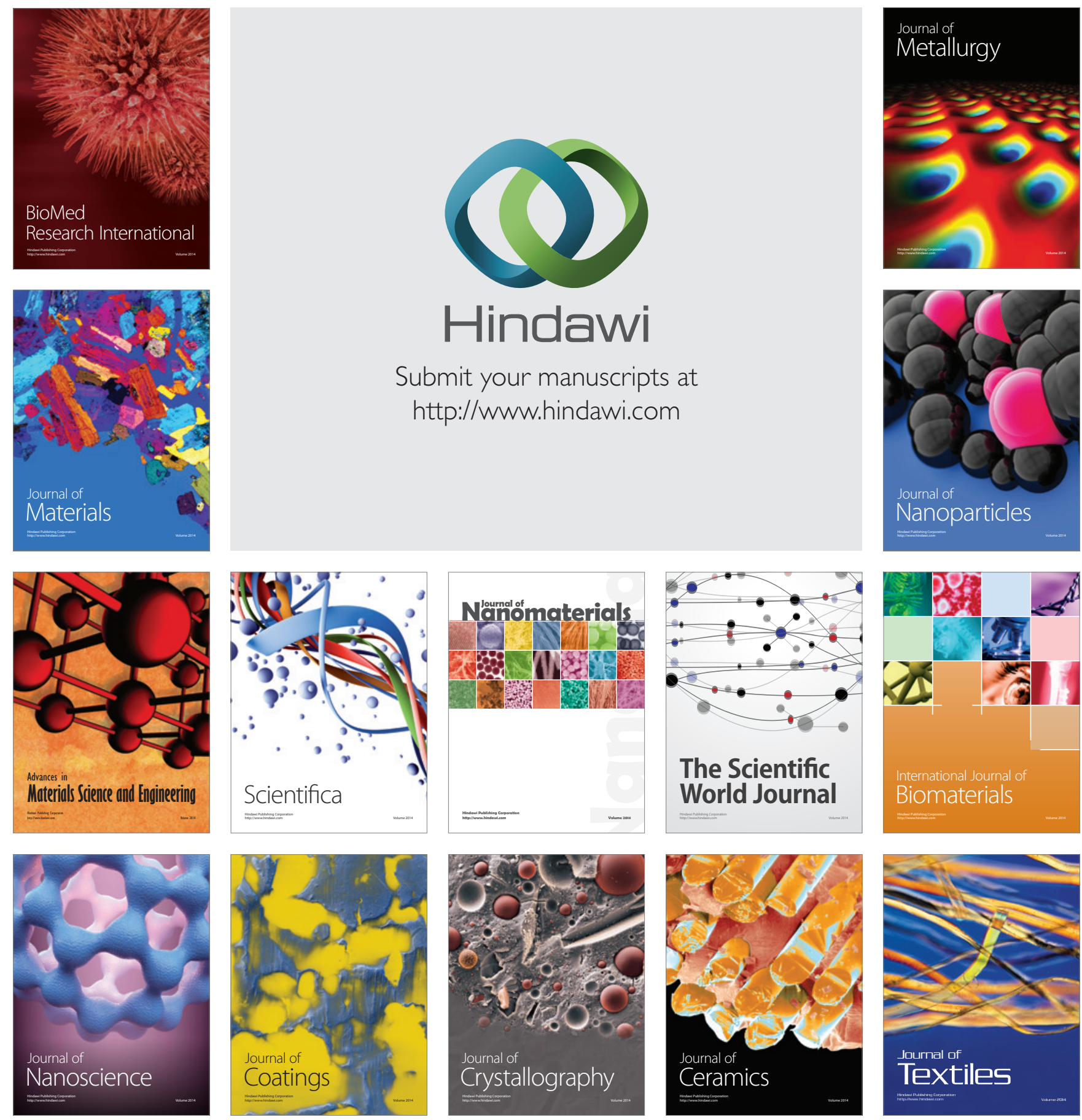